\title{
PHOTODEGRADATION OF CONGORED DYE USING HETEROGENEOUS PHOTOCATALYSIS UNDER ULTRA- VIOLET IRRADIATION
}

\author{
S. Arul ${ }^{1}$ and T. Senthilnathan ${ }^{2, *}$ \\ ${ }^{1}$ Research Scholar, Bharathiar University Coimbatore, (Tamilnadu) India. \\ ${ }^{2}$ Department of Physics, Vellammal Engineering College, Chennai, (Tamilnadu) India \\ *E-mail : kirthickarul@gmail.com
}

\begin{abstract}
Undoped Zinc oxide and Magnesium, Titanium codoped $\mathrm{ZnO}\left(\mathrm{S}_{\mathrm{A}}, \mathrm{S}_{\mathrm{B}}\right.$ and $\mathrm{S}_{\mathrm{C}}$ ) nanoparticles were synthesized from their precursors by soft chemical method. The structural and chemical characteristics of nanoparticles synthesized were analyzed utilizing various techniques such as XRD, FTIR, SEM-EDX, UV-Visible Spectroscopy and AFM while the photodegradation study of congo red was performed by UV/VIS spectrophotometry. The XRD results showed that the undoped $\mathrm{ZnO}$ and $\mathrm{Mg}$, Ti codoped $\mathrm{ZnO}$ nanoparticles were hexagonal wurtzite structure. The SEM analysis showed that synthesized nanoparticles were in the nano-range with varying morphology and also the purity of the sample was confirmed by EDX analysis. Undoped $\mathrm{ZnO}$ and $\mathrm{Mg}$, Ti codoped $\mathrm{ZnO}$ nanoparticles were used as photocatalyst for the photodegradation of congo red dye in aqueous medium under UV-light irradiation. The photodegradation study revealed that the Undoped $\mathrm{ZnO}$ and $\mathrm{Mg}$, Ti codoped $\mathrm{ZnO}$ nanoparticles degraded about 55\% and $91.5 \%$ of dye within 180 mins respectively. The activity of recovered undoped $\mathrm{ZnO}$ and $\mathrm{Mg}$ and Ti codoped $\mathrm{ZnO}$ nanoparticles were studied.
\end{abstract}

Keywords: ZnO, Nanoparticles, Soft-Chemical Method, Congored, Photodegradation.

○ RASĀYAN. All rights reserved

\section{INTRODUCTION}

Zinc oxide $(\mathrm{ZnO})$ has remarkable polar surfaces leading to the formation of a lot of nanostructures namely needles, films, rings, springs, bows and helices. Nowadays, $\mathrm{ZnO}$ has gained its popularity and consideration due to its indistinctive properties such as optical, semiconducting, piezoelectric and magnetic properties. The peculiar properties such as high catalytic efficiency and strong adsorption ability are possessed by $\mathrm{ZnO}$ nanostructures. The multiplicity of morphologies such as belts, ribbons, cables, rods, tubes, rings, tetrapods, spirals are the indistinctive properties of $\mathrm{ZnO}$ nanosystems that renders its contributions for a wide range of applications. $\mathrm{ZnO}$ nanomaterials is utilized as a photocatalytic agent for the photodegradation of industrial effluent, electric conductors, microbial inhibitors, etc. Technologies including alkoxide hydrolysis, gas phase thermal decomposition and micro-emulsion technologies for synthesizing $\mathrm{ZnO}$ nanostructures have been recorded. This investigation intended at synthesizing nano-sized $\mathrm{ZnO}$ and Magnesium (Mg), Titanium (Ti) codoped $\mathrm{ZnO}$ nanoparticles by soft chemical method and the chemical properties, compositions, particle morphology and photocatalytic performance of the synthesized nanomaterials were also studied.

\section{EXPERIMENTAL}

The chemicals required for the preparation of undoped $\mathrm{ZnO}$ and $\mathrm{Mg}$, Ti-doped $\mathrm{ZnO}$ nanoparticles by soft chemical method for photodegradation efficiency were purchased from Merck and used as precursors and distilled water was used as a solvent.

\section{Synthesis of Undoped ZnO Nanoparticles}

Zinc nitrate hexahydrate $(1 \mathrm{M})$ was used as a starting material and dissolved in $100 \mathrm{ml}$ distilled water using magnetic stirrer for 30 mins. A solution of $\mathrm{NaOH}(2 \mathrm{M})$ was mixed with starting solution to get a large

Rasayan J. Chem., 12(2), 891-897(2019)

http://dx.doi.org/10.31788/RJC.2019.1225175

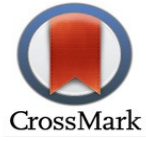


amount of white precipitate under constant stirring at $45^{\circ} \mathrm{C}$. By using distilled water, the precipitates were filtered and washed, then dehydrated at $120^{\circ} \mathrm{C}$ in hot air oven for four hours and white precipitates of synthesized materials were powdered in an agar mortar. The final powder was calcined at $450^{\circ} \mathrm{C}$ for 3 hours and allowed for cooling in furnace. The nanomaterials were collected for further characterization studies.

\section{Synthesis of Mg and Ti Codoped ZnO Nanoparticles}

Zinc nitrate hexahydrate $(0.98 \mathrm{M})$, Magnesium nitrate hexahydrate $(0.05,0.01 \& 0.15 \mathrm{M})$, Titanium (IV) isopropoxide $(0.15,0.01 \& 0.05 \mathrm{M})$ were used as precursors for the preparation of different concentrations $\left(\mathrm{S}_{\mathrm{A}}, \mathrm{S}_{\mathrm{B}}\right.$ and $\mathrm{S}_{\mathrm{C}}$ ) of $\mathrm{Mg}$ and $\mathrm{Ti}$ codoped $\mathrm{ZnO}$ by above-mentioned procedure and the final powder was collected for further characterization studies.

\section{Photodegradation Analysis}

About $10 \mathrm{mg} / \mathrm{L}$ of congo red dye and $50 \mathrm{ml}$ of distilled water with $40 \mathrm{mg}$ of Undoped $\mathrm{ZnO}$ nanomaterials were placed under UV irradiation for the degradation of dye in different time stretch of $(0,30,60,90$, 120,150 and 180 minutes). The influence of UV light sources on photo-degradation of congo red dye was supported with a $30 \mathrm{~W}$ mercury lamp and the decomposition effect was measured by UV-absorption measurement. The same method was applied for photodegradation efficiency of synthesized $\mathrm{Mg}$ and $\mathrm{Ti}$ codoped $\mathrm{ZnO}$ nanoparticles.

\section{XRD Analysis}

\section{RESULTS AND DISCUSSION}

Figure-1 evidenced the XRD configuration of undoped $\mathrm{ZnO}$ and $\mathrm{Mg}$ and $\mathrm{Ti}$ codoped $\mathrm{ZnO}\left(\mathrm{S}_{\mathrm{A}}, \mathrm{S}_{\mathrm{B}}\right.$ and $\left.\mathrm{S}_{\mathrm{C}}\right)$ nanoparticles synthesized by soft chemical method at $450^{\circ} \mathrm{C}$. All the peaks corresponded with hexagonal wurtzite structure of $\mathrm{ZnO}$ with lattice constants $a=b=0.32 \mathrm{~nm}$ and $c=0.52 \mathrm{~nm}$ (JCPDS Card No.361451). The peaks of (100), (101), (102), (110) and (103) were detected for pure $\mathrm{ZnO}$. The peaks of (102), (110) and (103) disappeared when doped metals were inserted into the $\mathrm{ZnO}$ nanoparticles ${ }^{6}$. The peaks of (100), (002) and (101) intensities continuously decreased with doping agents and Debye Scherrer's formula was used to calculate the average nanoparticle size. Debye Scherrer's formula is as below:

$$
\mathrm{D}=\frac{0.9 \lambda}{\beta \cos \theta}
$$

As per the formula, $\mathrm{D}$ indicates the average particle size, $\lambda$ indicates the incident wavelength of the X-ray beam, $\beta$ indicates the full-width at half-maximum (FWHM) and $\theta$ indicates the Bragg's diffraction angle correspondingly. The calculated particle sizes were $51 \mathrm{~nm}$ for undoped $\mathrm{ZnO}$ and $34 \mathrm{~nm}, 32 \mathrm{~nm}, 27 \mathrm{~nm}$ for samples $\mathrm{S}_{\mathrm{A}}, \mathrm{S}_{\mathrm{B}}$ and $\mathrm{S}_{\mathrm{C}}$ of $\mathrm{Mg}$, Ti codoped $\mathrm{ZnO}$ nanomaterials. The nanoparticles size of sample $\mathrm{S}_{\mathrm{C}}$ was decreased when compared with undoped $\mathrm{ZnO}$ and samples $\mathrm{S}_{\mathrm{A}} \& \mathrm{~S}_{\mathrm{B}}$ of $\mathrm{Mg} \&$ Ti codoped $\mathrm{ZnO}$.

Figure-2 evinced the Fourier Transform Infrared spectrum of prepared $\mathrm{ZnO} \mathrm{Np}$ 's and $\mathrm{Mg} \& \mathrm{Ti}$ codoped $\mathrm{ZnO}\left(\mathrm{S}_{\mathrm{A}}, \mathrm{S}_{\mathrm{B}}\right.$ and $\left.\mathrm{S}_{\mathrm{C}}\right)$ nanoparticles. The bands were perceived at $476 \mathrm{~cm}^{-1}$ for undoped $\mathrm{ZnO}$, and at $441 \mathrm{~cm}^{-}$ ${ }^{1}, 428 \mathrm{~cm}^{-1}$ and $438 \mathrm{~cm}^{-1}$ for samples $\mathrm{S}_{\mathrm{A}}, \mathrm{S}_{\mathrm{B}}$ and $\mathrm{S}_{\mathrm{C}}$ of $\mathrm{Mg} \& \mathrm{Ti}$ codoped $\mathrm{ZnO}$ nanoparticles were associated to metal oxide. It was acknowledged that the ranging of peak from $410-735 \mathrm{~cm}^{-1}$ was related to Zinc oxide as elicited by $\mathrm{Wu}$ et al $2015^{7}$. Pure Zinc Oxide and synthesized samples $\left(\mathrm{S}_{\mathrm{A}}, \mathrm{S}_{\mathrm{B}}\right.$ and $\left.\mathrm{S}_{\mathrm{C}}\right)$ bands were estimated as $1371 \mathrm{~cm}^{-1}$ and it was ascribed to the bending frequency of oxygen stretching mode. A band was noticed at $3443 \mathrm{~cm}^{-1}$ for undoped Zinc Oxide and the bands were found at 3431,3430 and $3430 \mathrm{~cm}^{-1}$ for $\mathrm{S}_{\mathrm{A}}, \mathrm{S}_{\mathrm{B}}$ and $\mathrm{S}_{\mathrm{C}}$ of $\mathrm{Mg}$, Ti codoped $\mathrm{ZnO}$ was ascribed to the stretching vibrations of $\mathrm{O}-\mathrm{H}^{8}$.

\section{Scanning Electron Microscope}

Figure- 3 evinced the surface morphology of Undoped $\mathrm{ZnO}$ and $\mathrm{Mg}$ and Ti codoped $\mathrm{ZnO}$ nanoparticles. The SEM images revealed that synthesized nanoparticles were in spherical morphology and the surface agglomeration was perceived. The nanoparticle size of undoped $\mathrm{ZnO}$ and $\mathrm{Mg}$, Ti codoped $\mathrm{ZnO}$ nanoparticles were calculated to be around $80-90 \mathrm{~nm}$.

\section{EDX Analysis}

Figure-4 shows EDX analysis of Undoped $\mathrm{ZnO}$ and $\mathrm{Mg}$, Ti codoped $\mathrm{ZnO}$ nanoparticles. Fig.-4(i) indicated that the elements of $\mathrm{Zn}$ and $\mathrm{O}$ were present in undoped nanomaterials and Fig.-4(ii) indicated that Mg, Ti, 
$\mathrm{Zn}$ and $\mathrm{O}$ were present in doped nanomaterials. The greater peak in the spectrum indicate the high concentration of element present in doped and undoped nanomaterials ${ }^{9}$.In Fig.-4 (i) \& (ii), Zn element exhibited higher peaks than another element such as $\mathrm{Mg}$, Ti and $\mathrm{O}$. The result of EDX analysis confirmed that there were no impurities present in the sample.

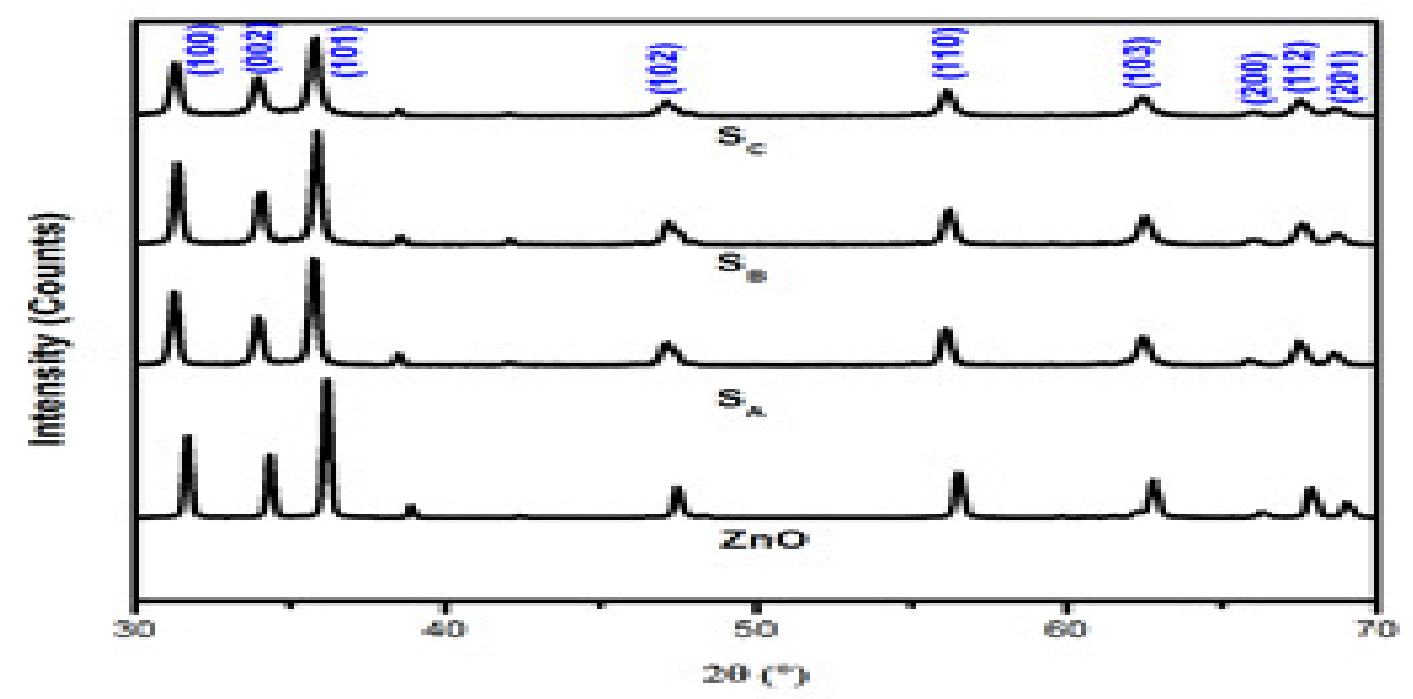

Fig.-1: XRD Patterns of (i) Undoped $\mathrm{ZnO}$ and (ii) $\mathrm{Mg}_{0.05} \mathrm{Ti}_{0.15}$ codoped $\mathrm{Zn}_{0.98} \mathrm{O}$ (iii) $\mathrm{Mg}_{0.01} \mathrm{Ti}_{0.01}$ codoped $\mathrm{Zn}_{0.98} \mathrm{O}$ (iv) $\mathrm{Mg}_{0.15} \mathrm{Ti}_{0.05}$ codoped $\mathrm{Zn}_{0.98} \mathrm{O}$

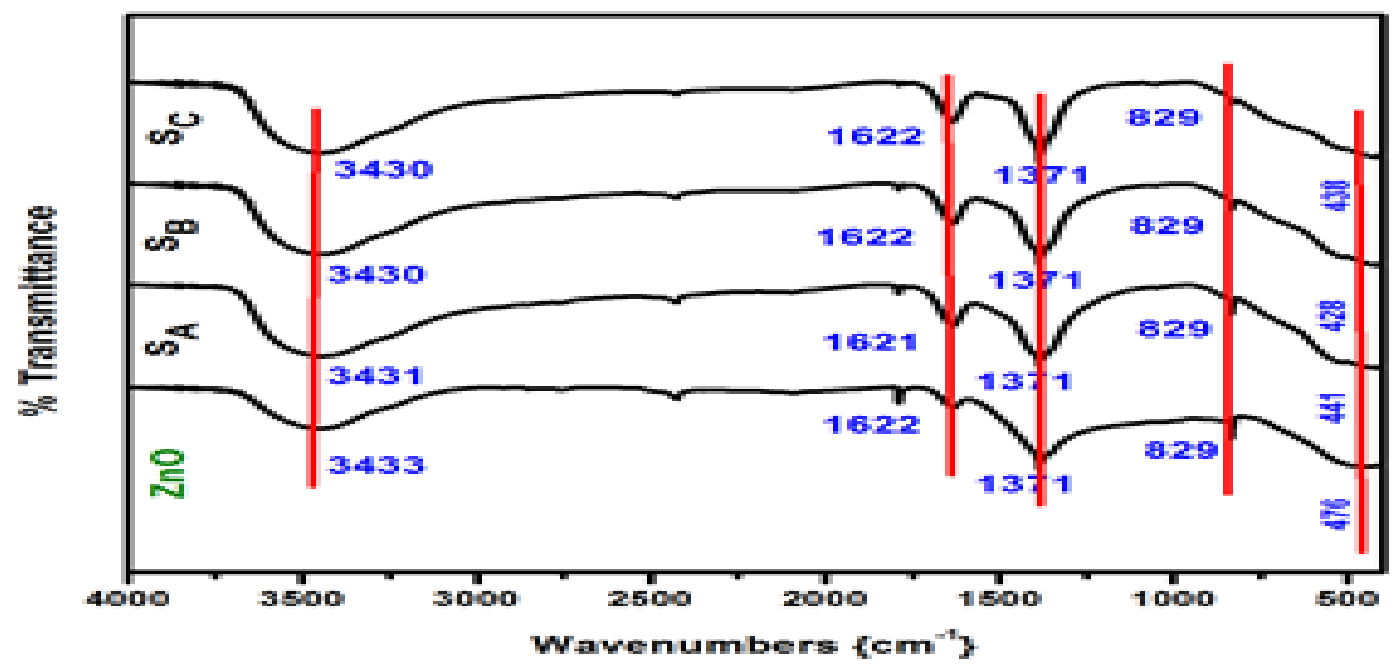

Fig.-2: Fourier Transform- Infrared Spectrum of (i) Undoped $\mathrm{ZnO}$ (ii) $\mathrm{Mg}_{0.05} \mathrm{Ti}_{0.15}$ codoped $\mathrm{Zn}_{0.98} \mathrm{O}$ (iii) $\mathrm{Mg}_{0.01}$ $\mathrm{Ti}_{0.01}$ codoped $\mathrm{Zn}_{0.98} \mathrm{O}$ (iv) $\mathrm{Mg}_{0.15} \mathrm{Ti}_{0.05}$ codoped $\mathrm{Zn}_{0.98} \mathrm{O}$

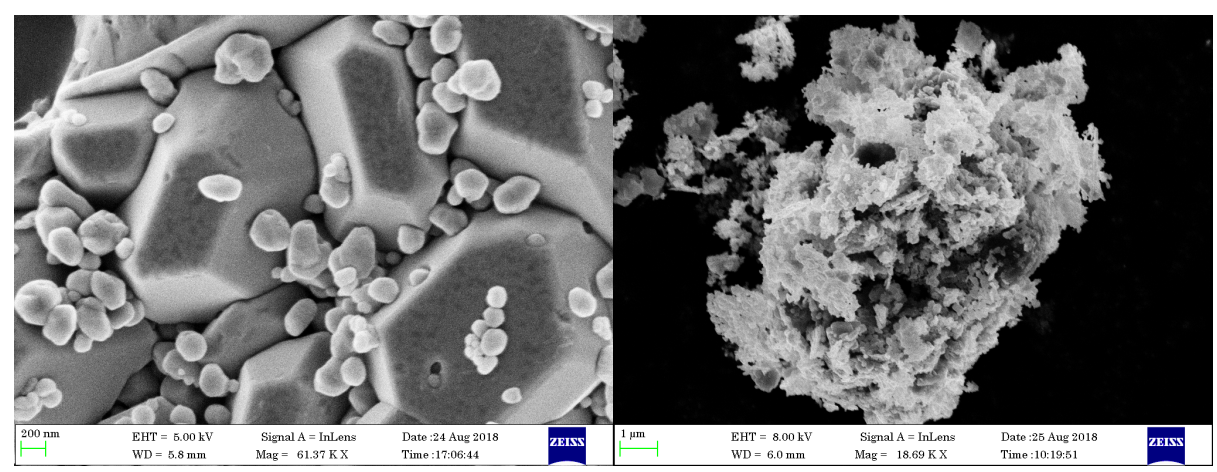

Fig.-3: SEM Analysis of (i) Undoped $\mathrm{ZnO}$ and (ii) $\mathrm{Mg}_{0.01} \mathrm{Ti}_{0.01}$ codoped $\mathrm{Zn}_{0.98} \mathrm{O}$ 
Vol. 12 | No. 2 |891 - 897| April - June | 2019

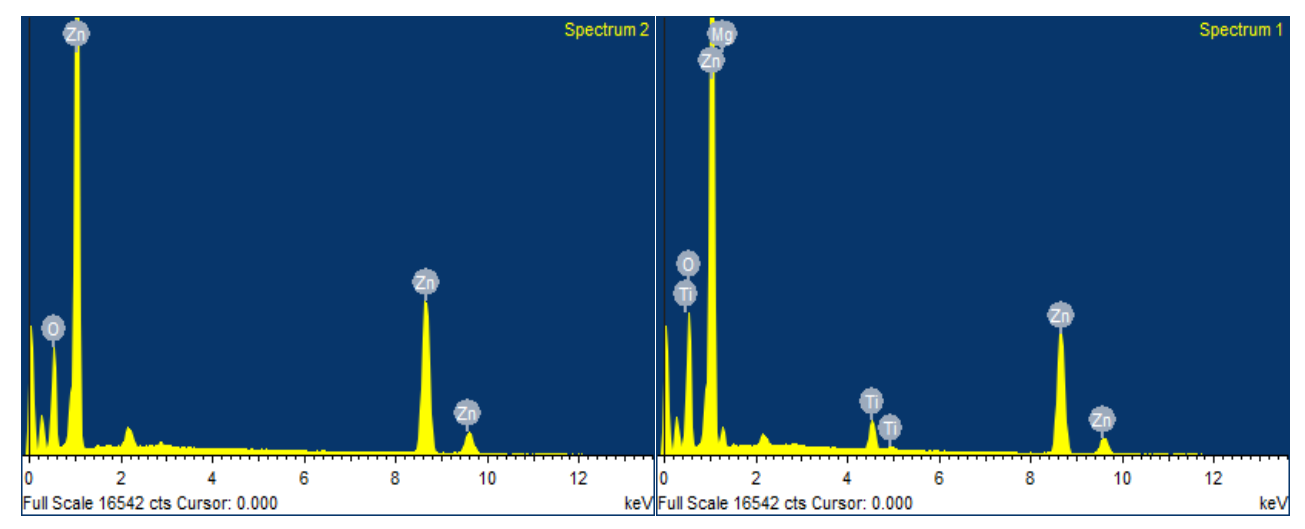

Fig.-4: EDX Analysis of (i) Undoped $\mathrm{ZnO}$ and (ii) $\mathrm{Mg}_{0.01} \mathrm{Ti}_{0.01}$ codoped $\mathrm{Zn}_{0.98} \mathrm{O}$

\section{Ultra Violet -Visible Spectroscopy}

Figure-5 evinced the optical absorption of undoped $\mathrm{ZnO}$ and $\mathrm{Mg}$, Ti codoped $\mathrm{ZnO}\left(\mathrm{S}_{\mathrm{A}}, \mathrm{S}_{\mathrm{B}}\right.$ and $\left.\mathrm{S}_{\mathrm{C}}\right)$ nanoparticles. The wavelength of synthesized nanomaterials optical absorption spectra was $379 \mathrm{~nm}$ for undoped $\mathrm{ZnO}$ and $373 \mathrm{~nm}, 371 \mathrm{~nm}, 371 \mathrm{~nm}$ for $\mathrm{S}_{\mathrm{A}}, \mathrm{S}_{\mathrm{B}}$ and $\mathrm{S}_{\mathrm{C}}$ of $\mathrm{Mg}$, Ti codoped $\mathrm{ZnO}$ nanoparticles respectively. The band gap energy values were calculated using the following equation,

$$
\mathrm{E}=(\mathrm{hc}) /(\lambda)
$$

As per the above equation, $\mathrm{h}$ indicates Planck's constant, $\mathrm{c}$ indicates the velocity of light and $\lambda$ indicates the wavelength of light and the obtained values were $3.72 \mathrm{eV}$ for undoped $\mathrm{ZnO}$ and $3.70 \mathrm{eV}, 3.68 \mathrm{eV}, 3.64 \mathrm{eV}$ for samples $\mathrm{S}_{\mathrm{A}}, \mathrm{S}_{\mathrm{B}}$ and $\mathrm{S}_{\mathrm{C}}$ of $\mathrm{Mg}$, Ti codoped $\mathrm{ZnO}$ nanoparticles. The small decrease in absorption was established in the presence of doping agents.

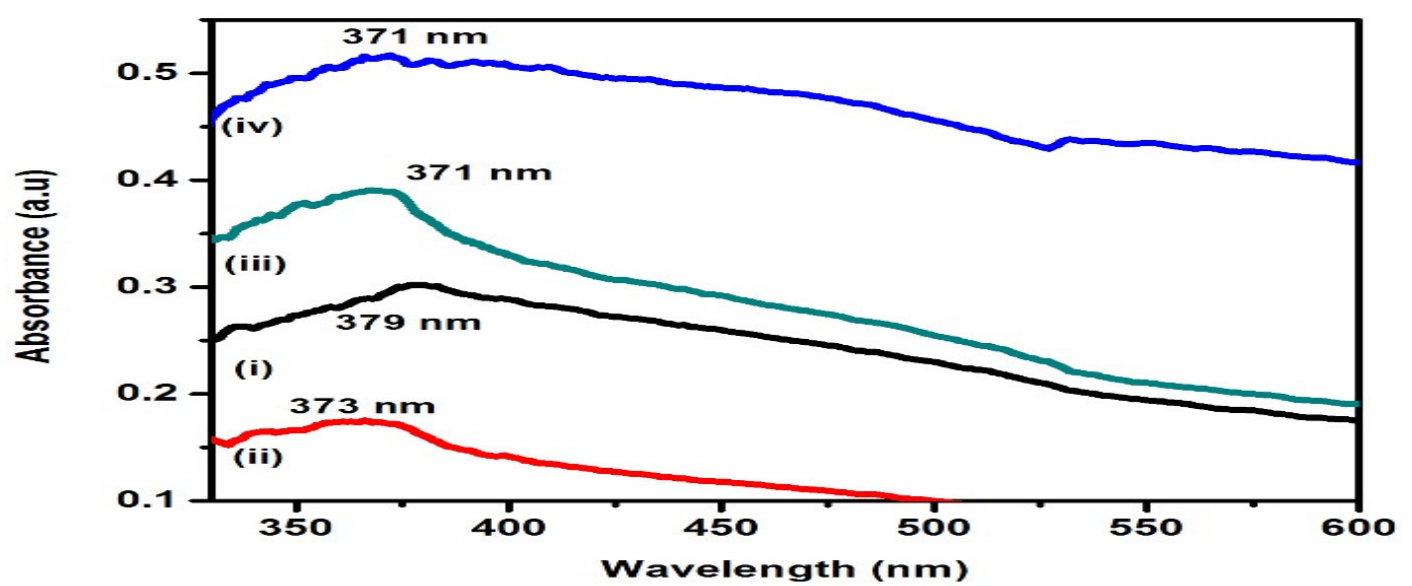

Fig.-5: Ultra-Violet -Visible Spectroscopic analysis of (i) Undoped $\mathrm{ZnO}$ (ii) $\mathrm{Mg}_{0.05} \mathrm{Ti}_{0.15}$ codoped $\mathrm{Zn}_{0.98} \mathrm{O}$ (iii)

\section{AFM Analysis}

$\mathrm{Mg}_{0.01} \mathrm{Ti}_{0.01}$ codoped $\mathrm{Zn}_{0.98} \mathrm{O}$ (iv) $\mathrm{Mg}_{0.15} \mathrm{Ti}_{0.05}$ codoped $\mathrm{Zn}_{0.98} \mathrm{O}$

Figure.6.shows the AFM analysis of synthesized undoped $\mathrm{ZnO} \& \mathrm{Mg}$, Ti codoped $\mathrm{ZnO}$ nanoparticles by soft chemical method. The average size of the particles was detected as $61 \mathrm{~nm}$ for Undoped $\mathrm{ZnO}$ and $41 \mathrm{~nm}$ for $\mathrm{Mg}$ and $\mathrm{Ti}$ codoped $\mathrm{ZnO}$ which was in good agreement with XRD analysis. The appearance of AFM images with regular shape and the random arrangement was observed ${ }^{10}$.

\section{Photodegradation of Undoped $\mathrm{ZnO}$ and $\mathrm{Mg}$, Ti Codoped $\mathrm{ZnO}$ Np's}

Figure-7 evinced the photo-degradation reaction for Congo red dye. The synthesized nanoparticles were absorbed by UV light, electrons were stimulated from the valence band to the conduction band. The light energy caused holes and reacted with water and hydroxyl radical was created. The hydroxyl radical was forceful, non-selective oxidant and oxidizing agent thereby resulting in the degradation of dyes. The light 
energy on reaction with electrons and in turn with molecular oxygen resulting in the generation of superoxide radical anions, which was responsible for the degradation of dye solution.
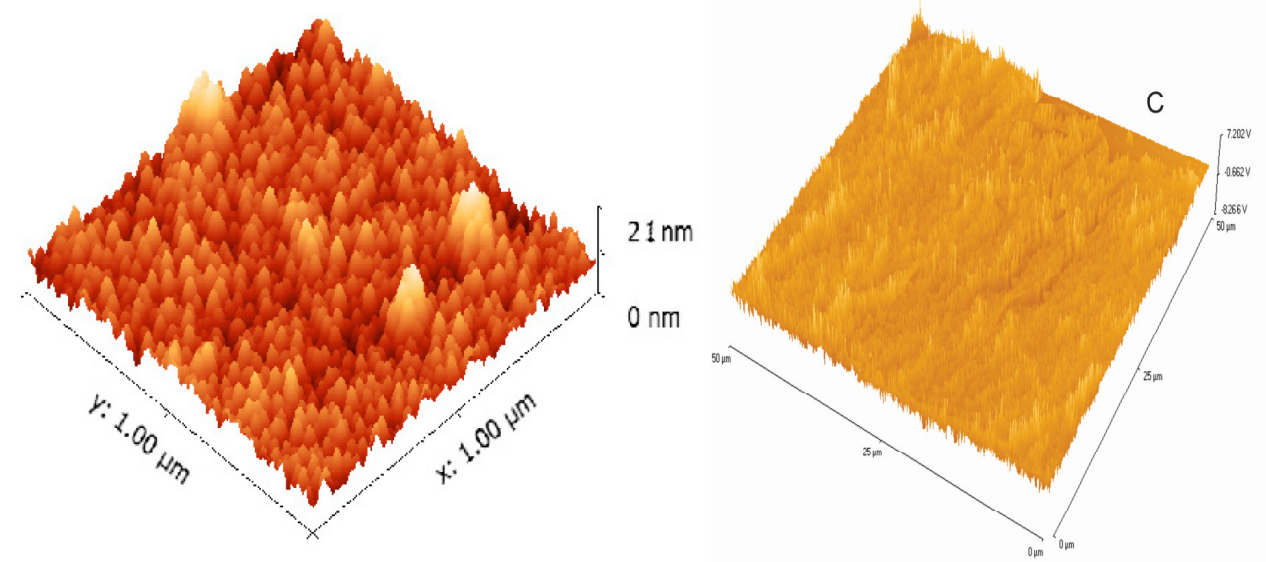

Fig.-6: AFM Images of (i) Undoped $\mathrm{ZnO}$ (ii) $\mathrm{Mg}_{0.01} \mathrm{Ti}_{0.01} \mathrm{Zn}_{0.98} \mathrm{O}$

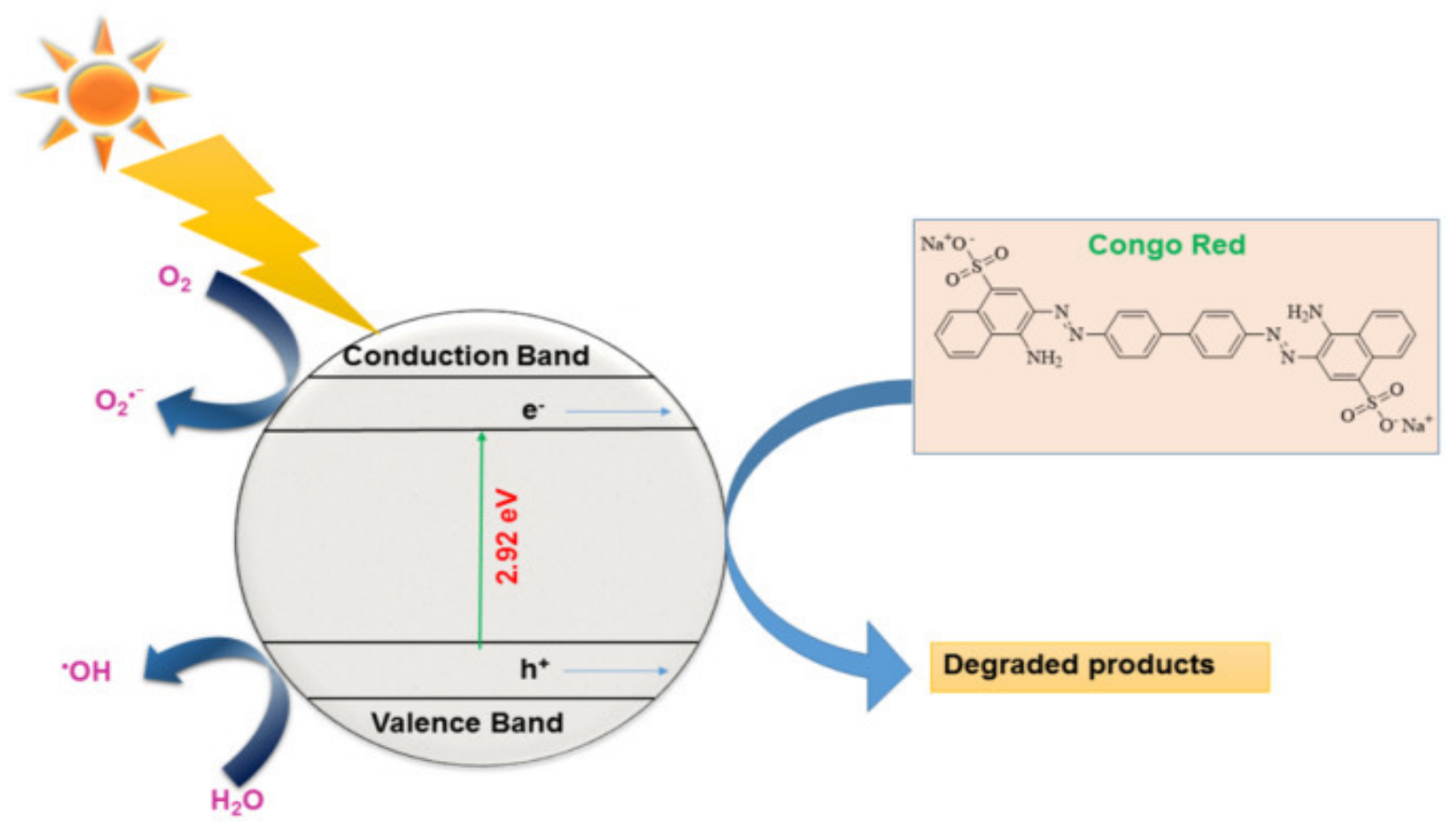

Fig.-7: Photodegradation Reaction of for Congo Red Dye

Photodegradation efficiency of Nanomaterials was calculated using the formula,

$$
\mathrm{D}(\%)=\left(\mathrm{A}_{0}-\mathrm{A}_{\mathrm{t}}\right) /\left(\mathrm{A}_{0}\right) \times 100
$$

Where, $\mathrm{D}$ is the degradation efficiency (in \%). $\mathrm{A}_{0}$ is the $\mathrm{UV}$ absorption of dye with sunlight irradiation time (0 min) and $A_{t}$ is the UV absorption of dye after UV-light irradiation (t-min).

Figure-8 (i) and (ii) shows the photodegradation efficiency of Undoped $\mathrm{ZnO}$ and $\mathrm{Mg}$, Ti-doped $\mathrm{ZnO}$ nanocomposites with UV irradiation in various time stretch $(30,60,90,120,150$ and 180 mins). The photodegradation efficiency values calculated were $55 \%$ for Undoped $\mathrm{ZnO}$ and $91.5 \%$ for $\mathrm{Mg}$ and $\mathrm{Ti}$ codoped $\mathrm{ZnO}$ nanoparticles. The results of Photodegradation analysis of congo red dye with Undoped and doped $\mathrm{ZnO}$ photocatalyst clearly presented a higher dye removal efficiency of the $\mathrm{Mg}$ and $\mathrm{Ti}$ codoped $\mathrm{ZnO}$ nanoparticles. Therefore, the experimental results concluded that the $\mathrm{Mg}$ and Ti codoped $\mathrm{ZnO}$ nanoparticles were a respectable dye removal catalyst comparing Undoped $\mathrm{ZnO}$ nanoparticles. This route could be suitable for sewage and industrial water treatment. 
RASĀYAN J. Chem.

Vol. 12 | No. 2 |891 - 897| April - June | 2019
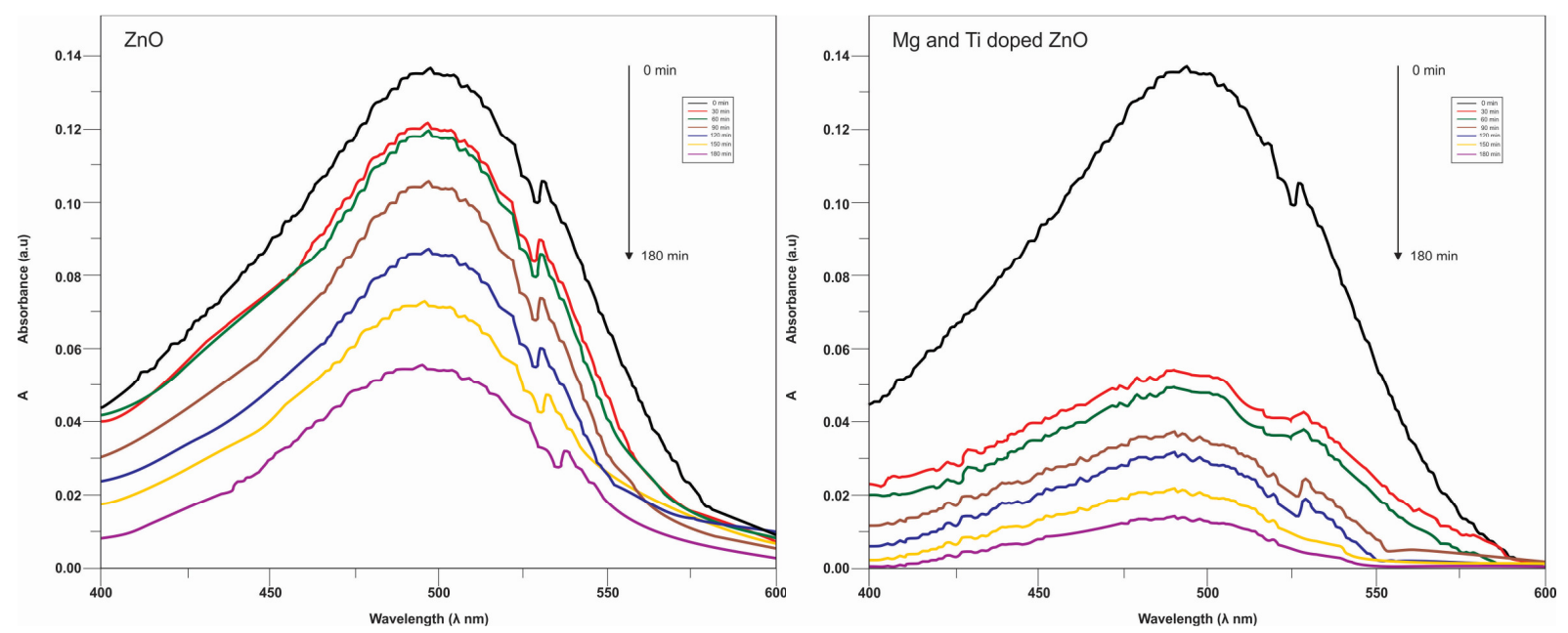

Fig.-8: Photodegradation Efficiency of (i) Undoped $\mathrm{ZnO}$ (ii) $\mathrm{Mg}_{0.01} \mathrm{Ti}_{0.01}$ codoped $\mathrm{ZnO}$

CONCLUSION

The present investigation revealed that a simple and low-cost technique of synthesis of Undoped $\mathrm{ZnO}$ and $\mathrm{Mg}$, Ti codoped $\mathrm{ZnO}$ nanoparticles by soft chemical method and its photodegradation efficiency. XRD results confirmed that hexagonal wurtzite structure of Undoped $\mathrm{ZnO}$ and $\mathrm{Mg}$, Ti codoped $\mathrm{ZnO}$ nanoparticles, then the average size of particle size calculated was $51 \mathrm{~nm}, 34 \mathrm{~nm}, 32 \mathrm{~nm} \& 27 \mathrm{~nm}$ using Debye Scherrer's equation. SEM images exhibited the formation of nanoparticles and surface agglomeration was observed.EDAX analysis results clearly indicated the percentage of presence of material and its purity. The synthesized nanocomposites band gap was calculated using UV-Vis analysis and the result was $3.72 \mathrm{eV}, 3.70 \mathrm{eV}, 3.68 \mathrm{eV}$ and $3.64 \mathrm{eV}$. From FT-IR studies, the peaks range $410-735 \mathrm{~cm}^{-1}$ verified the $\mathrm{ZnO}$ stretching mode. AFM study indicated the surface morphology and average particle size of nanomaterials. The photo-degradation efficiency of $\mathrm{Mg}$ and $\mathrm{Ti}$ codoped $\mathrm{ZnO}$ (91.5\%) nanomaterials had superior performance than undoped $\mathrm{ZnO}(55 \%)$ nanomaterials against congo red dye solution under UV irradiation $(180 \mathrm{~min})$. This process is useful for wastewater treatment in many industries for the removal of hazardous chemicals for ecological remediation.

\section{REFERENCES}

1. Lukas Schmidt, Mendejudit, Judith and MacManus-driscoll. L, Materials Today, 10(5), pp.40-48 (2007), DOI: 10.1016/S1369-7021(07)70078-0.

2. Xiaoqun Wei, Haichao Li, Shuixia Chen, Chane yuan and Qingyu Yuan, Crystal Research and Technology, 44(8), 861(2009), DOI: 10.1002/crat.200900247.

3. Pranita Lahure, Pooja Salunke, Rupam Soliwal, Anand Yadav, Shilpa Tripathi and A. A. Koser International Journal of Scientific Research in Physics and Applied Sciences, 3(1),32(2015).

4. Alessandro Di Mauro, Massimo Zimbone, Mario Scuderi, Giuseppe Nicotra, Maria Elena Fragalà and Giuliana Impellizzeri, Nanoscale Research Letters, 10, 484 (2015), DOI:10.1186/s11671-015-1126-6

5. Satyanarayana Talam, Srinivasa Rao Karumuri and Nagarjuna Gunnam, Nanotechnology, 1(2012), DOI: $10.5402 / 2012 / 372505$.

6. Duofa wang, Fangiie Wang, Haizheng Tao ,Xuecaihan, Xiujian Zhao, Tianjin Zhang, Hui huang, Hualiang, Wuqiu, Physics Prcedia, 48 (8),235 (2013), DOI: 10.1016/j.phpro.2013.07.037.

7. T. M. O. Ruellas, G. H. S. Domingos, L. O. O. Peçanha, S. C. Maestrelli and T. R. Giraldi, Ceramic 65(1), 47(2019), DOI: 10.1590/0366-6913201965s12609.

8. Sajid Husain, F. Rahman, Nasir Ali, Parvez Ahmad Alvi, Optoelectron, 1(1),28(2013), DOI:10.12691/joe-1-1-5.

9. Aleksandra B. Djurisic, Xinyi Chen , Yu Hang Leung, Alan Manching Na, Journal of Materials Chemistry 14(22),6526(2012), DOI:10.1039/C2JM15548F 


\section{RASĀYAN J. Chem.}

Vol. 12 | No. 2 |891 - 897| April - June | 2019

10. C. Manohara, G. Pavithra, M. Bououdina, S. Dhanapandian, P. Dhamodharan, Applied Nanoscience, 6(6), 815(2015), DOI: 10.1007/s13204-015-0493-8.

11. Khalid Saeed, Idrees Khan Tamanna Gul, Mohammad Sadiq, Separation Science and Technology, 51(8),3841(2016), DOI: 10.1080/01496395.2016.1154872

12. J. W. Elam, Z. A. Sechrist, S. M. George, Thin Solid Films, 41(1), 43(2002), DOI:10.1016/S00406090(02)00427-3

13. Sangeetha Nagarajan, Kumaraguru Arumugam Kuppusamy, Journal of Nanobiotechnology 11(39),1(2013), DOI: 10.1186/1477-3155-11-39.

14. S. Satheeskumar, K. Ramesh and N. Srinivasan, Digest Journal of Nanomaterials and Biostructures 9(4), 1323(2014).

15. V. Jeevanantham, K. V. Hemalatha, S. Satheeskumar, Journal of Ovonic Research, 14(4), 269 (2018). [RJC-5175/2019] 